\title{
PENGARUH MODEL PEMBELAJARAN QUANTUM DENGAN MEDIA AUDIO VISUAL TERHADAP HASIL BELAJAR IPA SISWA KELAS V SDN NGRUKEM KECAMATAN MLARAK KABUPATEN PONOROGO
}

\author{
Nindya Arianulva Saksitasari ${ }^{1}$, Hagus Muryanto $^{2}$, Raras Setyo Retno $^{3}$ \\ ${ }^{1,2,3)}$ Program studi PGSD, FIP IKIP PGRI Madiun \\ Jalan Setia Budi No. 85 Madiun \\ e-mail : ${ }^{1)}$ nindyaulva@gmail.com
}

Diterima 3 Agustus 2016, Disetujui 29 September 2016

\begin{abstract}
This research aims to determine whether there is influence of quantum learning model with the audio visual media to science learning outcomes student class V SDN Ngrukem Mlarak District of Ponorogo in academic year 2015/2016. Due to very low yields Science learning and teachers teaching with conventional methods. This study uses a one-group pretest-posttest design. The research sample of 15 students and research instruments in the form of a multiple choice test. Data were analyzed by using t-test. The result showed there are significant quantum learning model with audio visual media to science learning outcomes student class V SDN Ngrukem Mlarak District of Ponorogo in academic year 2015/2016.
\end{abstract}

Keyworsd: quantum model of learning, audiovisual media, Science learning outcomes

\section{PENDAHULUAN}

Model dan media pembelajaran memiliki peranan penting dalam menunjang pelaksanaan proses pembelajaran demi tercapainya tujuan pembelajaran. Dengan menggunakan model dan media pembelajaran, maka diharapkan proses pembelajaran menjadi menyenangkan dan siswa termotivasi untuk mengikuti kegiatan belajar. Pelajaran IPA yang menekankan pada belajar lingkungan sekitar dan alam mengharuskan siswa memahami secara detail apa saja yang ada di alam. Salah satu model pembelajaran yang sesuai digunakan pada pelajaran IPA adalah model pembelajaran quantum yang menekankan pada kebermaknaan dan kebermutuan proses pembelajaran. Model pembelajaran quantum akan mempertajam ingatan siswa karena siswa secara aktif belajar dan mengalami sendiri tahapan dalam proses pembelajaran. Selain itu dalam pelaksanaan pembelajaran IPA dengan model quantum jika digabung dengan media audio visual akan sangat menunjang proses pembelajaran, karena siswa akan sangat tertarik dengan penyajian materi menggunakan media audio visual dalam penelitian ini yaitu LCD proyektor, sehingga pembelajaran akan menyenangkan dan siswa tidak merasa terbebani. Pelaksanaan pembelajaran di SDN Ngrukem masih sangat jarang menggunakan model dan media pembelajaran, sehingga menjadi kurang aktif. Oleh karena itu diambil penelitian dengan menggunakan model pembelajaran quantum dengan media audio visual terhadap hasil belajar IPA untuk mengetahui adakah pengaruh model pembelajaran quantum dengan media audio visual terhadap hasil belajar IPA di SDN Ngrukem. Dengan dilakukannya penelitian ini diharapkan hasilnya dapat membantu mengatasi masalah atau kendala dalam pelaksanaan proses belajar mengajar IPA, agar kegiatan belajar mengajar lebih aktif, efektif dan efisien sehingga hasil yang dicapai lebih baik. Selain itu dapat 
melatih kemamapuan siswa dalam berfikir ilmiah sehingga tercipta generasi yang berkualita tinggi.

\section{METODE}

Penelitian ini dilaksanakan dengan
metode kuantitatif eksperimen dikarenakan fokus penelitian ini adalah apakah ada pengaruh model pembelajaran quantum dengan media audio visual terhadap hasil belajar IPA siswa kelas V SDN Ngrukem, sehingga diperlukan pengambilan data dengan tes yaitu pretest dan posttest. Sampel yang digunakan berjumlah 15 siswa. Teknik pengambilan sampel menggunakan sampling jenuh yaitu semua anggota populasi dijadikan sampel, karena populasi di kelas V SDN Ngrukem kurang dari 30 siswa. Peneliti mengambil data dari kelas pretest dan posttest yang berasal dari satu kelas dengan selang waktu tertentu. Hasil belajar pretest diambil sebelum siswa diberikan perlakuan dengan model quantum dengan media audio visual. Sedangkan hasil belajar posttest diambil setelah siswa diberikan perlakuan dengan model pembelajaran quantum dengan media audio visual. Dari data nilai pretest dan posttest akan dianalisis dengan uji normalitas menggunakan lilliefors dan uji homogenitas dengan uji-F dan uji hipotesis dengan uji-t dengan ketentuan $\mathrm{H} 1$ diterima jika $\mathrm{t}$ hitung $>\mathrm{t}$ tabel dan $\mathrm{H} 1$ ditolak jika $\mathrm{t}$ hitung $<\mathrm{t}$ tabel.

\section{HASIL DAN PEMBAHASAN}

Pengambilan data kelas pretest terhadap 15 siswa kelas V SDN Ngrukem diperoleh distribusi frekuensi kelas pretest pada tabel 1. Berdasarkan nilai pretest terhadap 15 siswa diperoleh nilai terendah 50 dan nilai tertinggi 75 . Sedangakan rata-rata kelas pretest 62 , jadi dapat disimpulkan bahwa nilai hasil belajar IPA kelas pretest tergolong kurang.
Tabel 1. Distribusi frekuensi

\begin{tabular}{cc}
\hline Nilai & Frekuensi \\
\hline $50-55$ & 3 \\
$56-60$ & 5 \\
$61-65$ & 5 \\
$66-70$ & 1 \\
$71-75$ & 1 \\
\hline Jumlah & 15
\end{tabular}

Sedangkan pengambilan data kelas posttest dilakukan setelah diberikan perlakuan dan diperoleh distribusi frekuensi nilai siswa kelas posttest pada tabel 2.

Tabel 2. Distribusi frekuensi nilai siswa kelas

\begin{tabular}{cc} 
post test & \\
\hline Nilai & Frekuensi \\
\hline $70-75$ & 3 \\
$76-80$ & 4 \\
$81-85$ & 2 \\
$86-90$ & 3 \\
$91-95$ & 3 \\
\hline Jumlah & 15 \\
\hline
\end{tabular}

Berdasarkan nilai posttest terhadap 15 siswa diperoleh nilai terendah 70 dan nilai tertinggi 95. Sedangkan ratarata kelas posttest 84, jadi dapat disimpulkan bahwa hasil belajar IPA kelas posttest tergolong baik. Sebelum dilakukan uji hipotesis, dilakukan uji prasyarat analisis yaitu uji normalitas dengan rumus lilliefors dan diperoleh data kelas pretest dan posttest berdistribusi normal. Setelah itu dilakukan uji homogenitas dengan rumus uji-F dan diperoleh data homogen, sehingga uji analisis penelitian ini dapat dilakukan dengan hipotesis uji-t. Ketentuan yang dijadikan pedoman dalam uji-t adalah $\mathrm{H} 1$ diterima jika $\mathrm{t}$ hitung $>\mathrm{t}$ tabel dan $\mathrm{H} 1$ ditolak jika $t$ hitung $<\mathrm{t}$ tabel. Setelah dianalisis dengan uji-t diperoleh $t$ hitung $>\mathrm{t}$ tabel. Sehingga dapat diambil kesimpulan bahwa dalam penelitian ini H1 diterima yaitu ada pengaruh model pembelajaran quantum dengan media audio visual terhadap hasil belajar IPA 
siswa kelas V SDN Ngrukem Kecamatan Mlarak Kabupaten Ponorogo Tahun Pelajaran 2015/2016.

Hasil perhitungan analisis data diperoleh nilai rata-rata (mean) sebesar 62. Sedangkan hasil belajar IPA dengan model pembelajaran quantum dengan media audiovisual yang diberikan pada 15 siswa telah diperoleh skor tertinggi 95 dan skor terendah 70. Dari hasil perhitungan analisis data diperoleh nilai rata-rata (mean) sebesar 84. Dan dari uji hipotesis penelitian kriteria uji: jika $\mathrm{t}$ hitung $>\mathrm{t}$ tabel maka dikatakan penelitian mempunyai pengaruh yang signifikan sesuai dengan hasil penelitian Purwono dkk (2014) menyatakan pelaksanaan penggunaan media audio visual dalam pembelajaran memberikan dampak positif bagi siswa. Siswa mendapatkan suasana pembelajaran yang baru, suasana kelas menjadi lebih interaktif, pembelajaran menjadi menarik, siswa menjadi lebih antusias dan lebih termotivasi untuk mengikuti pembelajaran.

Hasil belajar adalah perubahan perilaku individu yang meliputi ranah kognitif, afektif dan psikomotor diperoleh setelah siswa menyelesaikan program pembelajarannya melalui interaksi dengan berbagai sumber dan media belajar serta lingkungan belajar. Dari hasil yang diperoleh, maka dapat disimpulkan bahwa model pembelajaran quantum dengan media audio visual mempengaruhi hasil belajar IPA siswa kelas V SDN Ngrukem Kecamatan Mlarak Kabupaten Ponorogo sesuai dengan penelitian Purwono dkk (2014) menyatakan hasil belajar siswa setelah guru menggunakan media audio visual meningkat dengan dibuktikan hasil ulangan siswa nilai rata-rata kelas dan daya serap siswa dalam menerima pelajaran meningkat. Hasil penelitian tersebut diperkuat dengan adanya kenyataan yang terjadi di sekolah. Seperti hasil dari penelitian yang telah dilakukan, bahwa proses pembelajaran sangat dipengaruhi oleh adanya model dan media pembelajaran yang digunakan.

Penggunaan model pembelajaran quantum dengan media audio visual ini sebagai salah satu alternatif dalam meningkatkan hasil belajar IPA siswa kelas V SDN Ngrukem Kecamatan Mlarak Kabupaten Ponorogo pada semester genap ini serta proses pembelajaran selanjutnya. Selain itu model pembelajaran quantum dengan media audio visual juga dapat digunakan sebagai salah satu alternatif pada mata pelajaran lain. Tentunya sebagai guru harus memperhatikan materi yang ingin disampaikan sesuai atau tidak dan juga karakteristik siswa itu sendiri.

\section{SIMPULAN DAN SARAN Simpulan}

Berdasarkan hasil penelitian dan pembahasan dapat disimpulkan bahwa ada pengaruh model pembelajaran quantum dengan media audiovisual terhadap hasil belajar IPA siswa kelas V SDN Ngrukem Kecamatan Mlarak Kabupaten Ponorogo Tahun Pelajaran 2015/2016. Terlihat dari hasil uji-t hitung sebesar 3,79589858 dan nilai $t$ tabel 1,76131, sehingga diperoleh $\mathrm{t}$ hitung $>\mathrm{t}$ tabel berarti $\mathrm{H}_{0}$ ditolak dan $\mathrm{H}_{1}$ diterima. Sehingga model pembelajaran quantum dengan media audiovisual lebih efektif diterapkan pada mata pelajaran IPA kelas V SDN Ngrukem Kecamatan Mlarak Kabupaten Ponorogo.

\section{Saran}

Beberapa saran yang dapat penulis ajukan berkaitan dengan hasil penelitian ini antara lain:

1. Guru hendaknya memahami dan menguasai materi pembelajaran dengan menggunakan model dan media pembelajaran sebelum pelaksanaan pembelajaran untuk memaksimalkan proses pembelajaran. 
2. Model pembelajaran quantum dengan media audiovisual diterapkan agar siswa dapat belajar bermakna berdasar pengalaman belajarnya dan pelaksanaan pembelajaran tidak membosankan serta siswa menjadi lebih aktif.

3. Pihak sekolah hendaknya selalu memberikan dukungan kepada guru dalam memperkenalkan model-model pembelajaran yang inovatif serta penggunaan media pembelajaran sebagai pendukung pelaksanaan pembelajaran kepada siswa agar siswa lebih tertarik dan termotivasi dalam kegiatan pembelajaran, sehingga tujuan pembelajaran dapat tercapai secara maksimal.

\section{DAFTAR PUSTAKA}

Arsyad, A. (2011). Media Pembelajaran. Jakarta: Rajawali Press.

Isjoni. (2011). Pembelajaran Kooperatif: Meningkatkan Kecerdasan

Komunikasi antar Peserta Didik. Yogyakarta: Pustaka Pelajar.

Jalaludin. (2014). Filsafat Ilmu Pendidikan: Filsafat, Ilmu Pengetahuan, dan Peradaban. Jakarta: Rajawali Press.
Jihad, A. dan Haris, A. (2008). Evaluasi Pembelajaran. Yogyakarta: Multi Pressindo.

Kosasih, N. dan Sumarna, D. (2013). Pembelajaran Quantum dan Optimalisasi Kecerdasan. Bandung: Alfabeta cv.

Margaretha, dkk. (2007). Pendidikan IPA di SD. Bandung: UPI Press.

Purwono, dkk. (2014). Penggunaan Media Audio Visual pada Mata Pelajaran Ilmu Pengetahuan Alam di Sekolah Menengah Pertama Negeri 1 Pacitan. Jurnal Teknologi Pendidikan dan Pembelajaran. Vol 2. No 2.UNS.

Siregar, E. dan Nara, H. (2011). Teori Belajar dan Pembelajaran. Bogor: Penerbit Ghalia Indonesia.

Suprihatiningrum, J. (2013). Strategi Pembelajaran. Jogjakarta: Ar-Ruzz Media.

Susanto, A. (2013). Teori Belajar Dan Pembelajaran di Sekolah Dasar. Jakarta: Prenadamedia Group.

Turnip, J dan Panjaitan, K. (2014). Penerapan Model Quantum Learning untuk Meningkatkan Hasil Belajar Autocad Teknik Gambar Bangunan. Jurnal Teknologi Pendidikan. Vol 7. No 2. 